\title{
Gastrointestinal Tract Hemorrhage due to Angiodysplasia in Hutchinson Gilfort Progeria Syndrome
}

\author{
Serife Aktas ${ }^{\mathrm{a}}$, Mevlut Kiyak ${ }^{\mathrm{a}}$, Kamil Ozdil ${ }^{\mathrm{b}}$, Ibrahim Kurtca ${ }^{\mathrm{a}}$, Sevil Kibar ${ }^{\mathrm{a}}$, Suleyman Ahbab ${ }^{\mathrm{c}, \mathrm{e}}$, \\ Yusuf Karadeniz ${ }^{\mathrm{c}}$, Tayyibe Saler ${ }^{\mathrm{d}}$
}

\begin{abstract}
Hutchinson Gilfort Progeria Syndrome (HGPS) is an aging disease which encounters in childhood and includes a higher risk for atherosclerosis, cerebrovascular event, stroke and coronary artery disease. Angiodysplasia in the gastrointestinal (GIS) tract can be seen as a cause of hemorrhage, rarely. The case 15 years old female and admitted our center with a new onset nausea, vomit, and described the blackness in the stool. In the patient's history, HGPS was diagnosed, according to medical file records. The patient was hospitalized with a risk of possible acute GIS tract hemorrhage. Medical treatment was administered and gastroscopy underwent in our clinic. Gastric angiodisplasy was identified.In the literature, there was not coincided HGPS case with hemorrhagic angiodisplasia, commonly. This case report was represented to emphasize HGPS associated angiodisplasia as a rare cause of anemia and GIS tract hemorrhage.
\end{abstract}

Keywords: Hutchinson Gilfort Progeria Syndrome; Angiodysplasia; Gastrointestinal hemorrhage

\section{Introduction}

Hutchinson-Gilfort Progeria Syndrome (HGPS) is an extremely rare genetic disorder that can be seen after birth, pre-

Manuscript accepted for publication July 5, 2013

${ }^{a}$ Umraniye Training and Research Hospital, Internal Medicine Clinic, Istanbul, Turkey

${ }^{\mathrm{b}}$ Umraniye Training and Research Hospital, Gastroenterology Clinic, Istanbul, Turkey

${ }^{c}$ Haseki Training and Research Hospital, Internal Medicine Clinic, Istanbul, Turkey

dAdana Numune Training and Research Hospital, Internal Medicine Clinic, Adana, Turkey

${ }^{\mathrm{e}}$ Corresponding author: Suleyman Ahbab, Haseki Training and Research Hospital, Internal Medicine Clinic, Istanbul, Turkey. Email: drsahbab@hotmail.com

doi: http://dx.doi.org/10.4021/jmc1379w maturity and a cause of aging. It seems 1 of 8 million children in the world. Jonathan Hutchinson and Gilford Progeria have been reported, for the first time in England in 1886. Progeria is a term includes disproportionately long head, lipodistrophy, limitation of knee, and elbow extension, common view of aging [1]. Dyck et al. reported the 14-year-old progeria patient and undergone percutaneous transluminal angioplasty of coronary artery bypass surgery in 1987 [2]. Also, Fatunde et al. reported severe form of Progeria in 35th gestational weeks fetus of a women in 1990 [3]. Children with HGPS at birth, is usually normal. Skin changes and inability to weight gain occurre in the first $2-12$ months of life time.

Progeria displays alopecia, thin skin structure, subcutaneous fat loss, periarticular fibrosis, skeletal hypoplasia, dental subtraction delay, atherosclerosis, metabolic changes, and mandibular hypoplasia. Atherosclerosis starts in first five years [4]. Progeria has an autosomal recessive inheritance. It was defined, Laminin A (LMNA) gene point mutations in HGPS individuals. LMNA gene encodes laminin A and laminin C. Laminin type A is an important structural component nuclear membrane. These findings can provide the general process of aging and important clue about the disease [5].

Angiodisplasia is responsible for $6 \%$ of all GIS tract hemorrhage and the most common bleeding cause in individuals over the age of 60 after diverticulosis. Angiodysplasia formation mechanism is not clear, but is thought to be due to aging effects of the changes in the vascular bed. Usually localized in the cecum and right colon. Clinically, these patients may come with without bleeding, iron deficiency anemia. Gastrointestinal tract bleeding of unknown cause, is responsible for $30 \%$ to 40 small bowel angiodysplasia. Usually, bleeding angiodysplasia stops by itself [6]. This case is presented to underline HGPS associated angiodysplasia as a rare cause of GIS tract bleeding.

\section{Case Report}

15 years female Progeria patient which the diagnose was established before. The patient admitted our center with dyspeptic symtoms such as neusea, vomit, bloating and de- 

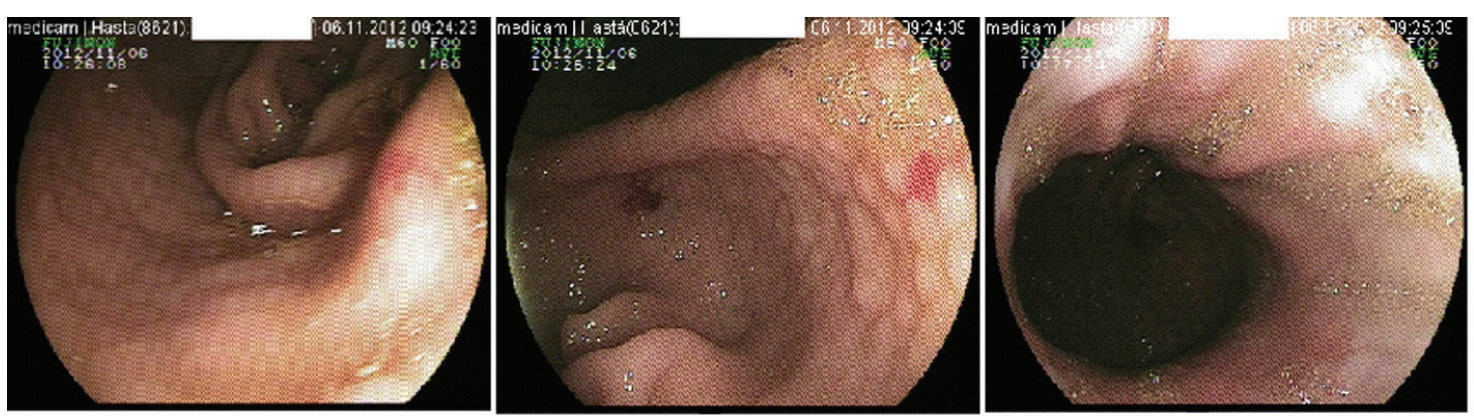

Figure 1. Endoscopic view of the gastric angiodysplasia.

scribed the blackness in the stool. In the patient's history, GIS tract hemorrhage was occured and treated in the another region hospital, two months ago. In the physical examination, decreased subcutaneous fat tissue, thin skin structure, micrognaty, thin top and bottom lip structure were inspected. Cardiovascular and respiratory system examination displayed normal findings. Melena was not examinated in rectal examination. Laboratory findings were normal between ranges except mild hypochromic anemia and hypothyroidism; hemoglobin $12 \mathrm{~g} / \mathrm{dL}(12-18)$, hematocrit $38 \%$ (37 48), creatinine $0.6 \mathrm{mg} / \mathrm{dL}(0.5-1.1)$, ferritin $139 \mathrm{ng} / \mathrm{mL}$ (4.6 - 204), iron $19 \mu \mathrm{g} / \mathrm{dL}(50$ - 170), thyroid stimulan hormone (TSH) $6.1 \mathrm{mIU} / \mathrm{L}(0.4-3.4)$, free T4 $1.0 \mathrm{ng} / \mathrm{dL}(0.9-1.5)$, anti thyroglobulin $113 \mathrm{IU} / \mathrm{mL}(0-57)$, anti thyroid peroxidase $267 \mathrm{IU} / \mathrm{mL}$ (0 - 64), sedimentation $39 \mathrm{~mm} /$ hour. Intact and diffuse type angiodysplasia on the gastric mucosa was identified by the gastroscopy as shown in the Figure 1. There were no any bleeding signs and medical treatment (proton pump inhibitor and sucralfate) was applied. Also, hypothyroidism was treated by the levo-thyroxin preparate. For the mild hypochromic and iron deficient anemia, iron containing preparate added to the treatment after discharge.

\section{Discussion}

Anjiodisplasia is the the most common cause of gastrointestinal tract bleeding in the elderly. Kendir et al, investigated in their patients group that the etiology of iron deficiency anemia over the age of 60 includes, $61 \%$ of patients were angiodysplasia, $21 \%$ inflammation, $19 \%$ polyps, $13 \%$ diverticulum, $2.4 \%$ associated with the malignancy [7]. Angiodysplasia is usually localized to the cecum and right colon and bleeding usually stops by itself. Angiodysplasia formation mechanism is not clear, but changes in the vascular bed can be developed a result of aging. Ouakaa et al, investigated 54 patients with angiodysplasia and revealed approximately $85 \%$ colonic involvement [8]. Early atherosclerosis and cerebrovascular disease occure in Progeria syndrome. Silvera et al, described cerebrovascular events (ischemia, infarct) in $60 \%$ of 24 Progeria patients [9]. In this presentation, gastroscopy was applied because of the existing signs and a gastric hemorrhage history, two months ago and angiodysplasia was detected.

Angiodysplasia and GIS hemorrhages are uncommon features in childhood. Chuang et al, investigated 18 children (14 male and 4 female) who hospitalised and treated because of angiodysplasia associated GIS bleeding between years of 2004 and 2008. They determined that the localisation of angiodysplasia on colon and terminal ileum, commonly [10]. Kimpton et al, declared hematochesia due to jejunal angiodysplasia, in 10 years old child [11]. Also, Al Mehaidip et al, displayed angiodysplasia associated bleeding in 2, 5 and 7 years old children and published [12]. According to the literature, angiodysplasia is an elderly health problem and an uncommon reason of GIS tract hemorrhage. Iron deficiency anemia can be developed among angiodysplasia related HGPS patients. It must be taken into account of etiological searching of the iron deficiency anemia.

\section{References}

1. Jones KL.Progeria syndrome. In: Smith's recognizable patterns of human malformation. 4th. ed Philadelphia:W. B. Saunder Company; 1988. p:118-119.

2. Ogihara T, Hata T, Tanaka K, Fukuchi K, Tabuchi Y, Kumahara Y. Hutchinson-Gilford progeria syndrome in a 45-year-old man. Am J Med. 1986;81(1):135-138.

3. Parkash H, Sidhu SS, Raghavan R, Deshmukh RN. Hutchinson-Gilford progeria: familial occurrence. Am J Med Genet. 1990;36(4):431-433.

4. Fatunde OJ, Benka-Coker LBO, Scott- Emuakpor AB. Familial occurrence of progeria (Hutchinson- Gliford progeri syndrome).Am J Hum Genet 1990; 47:55

5. Zucchero T, Ahmed S. Genetics of proliferative aging. Exp Gerontol. 2006;41(10):992-1000.

6. D'Souza AL. Ageing and the gut. Postgrad Med J. 2007;83(975):44-53.

7. Craig O. The radiology of small bowel lesions. Postgrad Med J. 1970;46(531):44-51.

8. Kendir M, Karaali Z, Baysal B. Anemi nedeni ile tetkik 
edilen hastalarda kolonoskopide anjiodisplazi gorulme siklıgi. Akademik Gastroenteroloji Dergisi 2004; 3(1): 24-27.

9. Silvera VM, Gordon LB, Orbach DB, Campbell SE, Machan JT, Ullrich NJ. Imaging characteristics of cerebrovascular arteriopathy and stroke in HutchinsonGilford progeria syndrome. AJNR Am J Neuroradiol. 2013;34(5):1091-1097.

10. Chuang FJ, Lin JS, Yeung CY, Chan WT, Jiang CB, Lee
HC. Intestinal angiodysplasia: an uncommon cause of gastrointestinal bleeding in children. Pediatr Neonatol. 2011;52(4):214-218.

11. Kimpton JA, Bowen JC, Craigie RJ. Paediatric angiodysplasia of the jejunum: a case report and review of the literature. Scott Med J. 2012;57(4):247.

12. Al-Mehaidib A, Alnassar S, Alshamrani AS. Gastrointestinal angiodysplasia in three Saudi children. Ann Saudi Med. 2009;29(3):223-226. 